\title{
Multi-criteria evaluation of sources for self-help domestic water supply
}

\author{
C. C. Nnaji ${ }^{1}$ A. Banigo ${ }^{1}$
}

Received: 19 December 2015 / Accepted: 27 December 2017 / Published online: 24 January 2018

(c) The Author(s) 2018. This article is an open access publication

\begin{abstract}
Two multi-criteria decision analysis methods were employed to evaluate six water sources. The analytical hierarchical process (AHP) ranked borehole highest with a rank of 0.321 followed by water board with a rank of 0.284 . The other sources ranked far below these two as follows: water tanker (0.139), rainwater harvesting (0.117), shallow well (0.114) and stream $(0.130)$. The Technique for Order Performance by Similarity to the Ideal Solution (TOPSIS) ranked water board highest with a rank of 0.865 , followed by borehole with a value of 0.778 . Quality and risk of contamination were found to be the most influential criteria while seasonality was the least.
\end{abstract}

Keywords Multi-criteria $\cdot$ Water $\cdot$ Ranking $\cdot$ AHP $\cdot$ TOPSIS $\cdot$ Criteria $\cdot$ Nigeria

\section{Introduction}

Water is critical both for the survival and continued existence of humanity. There is abundance of water on the earth, but most times, it exists in forms that are not directly accessible to man. Adequate water supply remains a critical aspect of industrialization and urbanization. Tshikolomo et al. (2012) observed that lack of access to safe and improved water supply is a major concern in developing countries. Most cities in Sub-Saharan Africa experience acute domestic water shortages due to additive effects associated with lack of efficient, socio-politically acceptable, and transparent management of water resources (Mark and Tafdzwa 2015). The failure of the government to provide adequate water even at a fee has driven many people to resort to selfhelp methods of water supply. It has been well established in the literature that some urban dwellers in Nigeria and other developing countries rely on vendors for water supply, the most prevalent of which are the water tankers. Adeoye, Adeolu and Ibrahim (2013) observed that lack of access to adequate clean water compels people to use contaminated

$\triangle$ C. C. Nnaji

chidozie.nnaji@unn.edu.ng

A. Banigo

banigoamy@gmail.com

1 Department of Civil Engineering, University of Nigeria, Nsukka, Enugu State, Nigeria water which usually impairs their health. Water from such sources is responsible for a wide variety of sicknesses such as cholera, dysentery, diarrhea, typhoid, shigellosis, salmonellosis, ascariasis, schistosomiasis, etc. (Ukpong and Okon 2013; Carter et al. 1999; John-Dewole 2012). Besides causing water stress and diseases, water shortage can result in decline in hygiene and overall quality of life. Water shortage manifests in improperly flushed toilets, poorly washed dishes and clothes, as well as compromised personal hygiene.

Generally, as noted by Giupponi and Sgobbi (2013) environmental issues are always the object of diversified and often conflicting interests (economic, social, and cultural). Water supply delivery management involves many factors, quantitative and qualitative, tangible and intangibles, and may include interest groups and stakeholders (Okeola and Sule 2012). Lade, Oloke et al. (2012) rightly observed that problems associated with sustainable urban supply are challenging and have no correct answer. Experts are beginning to come to terms with the fact that resource management problems are better tackled from a multi-disciplinary perspective. Multi-criteria decision making analysis (MCDA) enables decision makers to transparently evaluate alternatives from a multi-disciplinary and holistic perspective than from the bias of a single discipline. MCDA has gained credibility in the field of integrated water resources management because of its ability to overcome human limits to intuitively combine different sources of information in a rational way without requiring the estimation of monetary values 
(Giupponi and Sgobbi 2013). MCDA is the general field of study which includes decision making in the presence of two or more conflicting objectives and/or decision analysis processes involving two or more attributes (Tecle and Duckstein 1994). It is a holistic approach to solve challenging problems and it is a means of combining several variables and models to incorporate all necessary interacting components in decision making process (Al-Zubi et al. 2002). It enables the synthesis of conflicting needs and supporting information in a coherent framework and allows decision makers to identify critical pathways or activities in dealing with complex decision problems (Pietersen 2006). MCDA does not necessarily yield the best option from the perspective of any particular discipline; rather it yields a compromise solution. Othman et al. (2014) defined a compromise solution as a solution that considers interaction among criteria and also decision makers' needs. MCDA is recommended because it permits evaluation of ecological and social as well as economic criteria (Ramsar Convention Secretariat 2010). It allows for the integration of tangible and intangible, measurable and unquantifiable criteria, which are characteristic of water resources management problems, in the decision making process.

Miller and Belton (2014) observed that MCDA methods are well suited to water policy problems because they facilitate balancing multiple objectives and assessing priorities among values that are often not easily monetized. Numerous research articles involving the application of MCDA in water resources management have been published the world over. However, apart from South Africa, this powerful tool is hardly utilized by water resources experts in Africa and other developing countries of the world. For the purpose of this paper, only published articles in Africa and developing countries will be mentioned. Jaber and Mohsen (2001) employed AHP to develop a decision support system for the evaluation and selection of potential non-convectional water resources supply in Jordan and concluded that desalination followed by rainwater harvesting was the most promising option. Miller and Belton (2014) employed a United Nations Environment Programme multi-criteria framework for climate change analysis (MCA4Climate) to investigate the use of water policy development for climate change adaptation in Yemen. Awadallah and Awadallah (2014) employed MCDA to evaluate water allocation policies in El-khemís, Algiers. El-Zayat (2014) developed a multi-criteria framework to benchmark the performance of the water sectors in the Nile basin. El-Gafy, El-Ganzori and Mohamed (2013) assessed irrigation water in the Egyptian Governorate using MCDA. Mutikanga et al. (2011) employed MCDA to evaluate water loss reduction options in Kampala using seven evaluation criteria characterized by financial-economic, environmental, public health, technical and social impacts. Piertersen (2006) applied MCDA to develop policy responses and strategies for groundwater management at community and catchment scales in South Africa. Musungu et al. (2012) employed MCDA in conjunction with geographic information system (GIS) to assess the flood vulnerability of informal settlements of Cape Town, South Africa. Prasad et al. (2004) used MCDA to prioritize water management alternatives in South Africa by integrating economic, socio-economic and hydrological criteria. Tashome et al. (2014) utilized MCDA to evaluate soil and conservation measures in Northwestern Ethiopia. Lasage (2007) used a multi-criteria based software called DEFINITE to analyze the water resources management strategies in Kutiu, Kenya. Okeola and Sule (2012) used AHP to evaluate alternative sources for urban water supply in Offa, Nigeria.

This study is intended to serve as a guide to households in selecting sources or a combination of source for domestic water supply. Since the result of this research may not be universally applicable, it is necessary to define prevailing conditions under which this study was conducted. The scope of this research is meant to cover South Eastern, South Western, South Southern and North Central Nigeria and other areas with similar climatic and demographic characteristics as given below:

Temperature- $20-33{ }^{\circ} \mathrm{C}$

Annual Rainfall depth-900-4000 mm

Rainfall duration-March-October

Ecological zone-Tropical Rainforest, Derived Guinea Savannah

Groundwater Level—Variable

\section{Methodology}

Two MCDA methods were used in this study, namely Analytic Hierarchical Process (AHP) and Technique for Order Performance by Similarity to the Ideal Solution (TOPSIS). Lade et al. (2012) proposed AHP for solving water supply problems and a framework for improved rainwater harvesting system. Besides Musungu et al. (2012) observed that MCDA procedures involving pairwise comparison and trade-off analysis methods are the best. All MCDA methods have advantages and disadvantages. The advantages and disadvantages of AHP and TOPSIS have been summarized in Table 1 as elicited from Velasquez and Hester (2013).

Obviously, the advantages of the two methods outweigh their disadvantages; hence they have found wide applications in various and varied decision making problems. AHP has found wide application in resource management, corporate policy and strategy, public policy, political strategy and planning. AHP is ideal for resource management problems because it takes away the risk of rank reversal by having a limited number of alternatives to start with (Velasquez and Hester 2013). In the same vein, TOPSIS has found wide application 
Table 1 Strengths and limitations of AHP and TOPSIS

\begin{tabular}{|c|c|c|c|}
\hline \multicolumn{2}{|l|}{ AHP } & \multicolumn{2}{|l|}{ TOPSIS } \\
\hline Strength & Limitation & Strength & Limitation \\
\hline Easy to use & $\begin{array}{l}\text { Adversely affected by Interdependence } \\
\text { of criteria and alternatives }\end{array}$ & Simple to apply & $\begin{array}{l}\text { Its use of Euclidean } \\
\text { distance disregards } \\
\text { correlation among } \\
\text { attributes }\end{array}$ \\
\hline $\begin{array}{l}\text { Use of pairwise comparison enables easy } \\
\text { weighting of coefficients and comparison of } \\
\text { alternatives. }\end{array}$ & Possibility of inconsistency in judgment & It is programmable & $\begin{array}{l}\text { Inconsistency can } \\
\text { arise when the } \\
\text { number of attrib- } \\
\text { utes is large }\end{array}$ \\
\hline $\begin{array}{l}\text { Easily scalable and can adjust in size to } \\
\text { accommodate decision making problems due } \\
\text { to its hierarchical structure }\end{array}$ & Risk of rank reversal & $\begin{array}{l}\text { Steps remain the same } \\
\text { regardless of the number of } \\
\text { attributes }\end{array}$ & \\
\hline \multicolumn{4}{|l|}{ Ability to handle large and complex problems } \\
\hline Not data intensive & & & \\
\hline
\end{tabular}

in supply chain management and logistics, engineering and manufacturing systems, business and marketing management, environmental management, human resource management and water resources management. Its ease of use has kept it popular and its results have always been confirmed by other MCDA methods. Hence it is often applied as a check for other methods (Velasquez and Hester 2013).

\section{Procedure for AHP}

The basic procedure for AHP have been otlined below (see also Saaty 2008)

\section{Step one: structuring a decision problem and selection of criteria}

The first step is to decompose a decision problem into its constituent parts. In its simplest form, this structure comprises a goal or focus at the topmost level, criteria (and sub-criteria) at the intermediate levels, while the lowest level contains the alternatives (water sources). Six common sources of water in Nigeria were selected, namely borehole, rainwater harvesting, shallow well, stream/river, water tanker and water board. The water board refers to the municipal water supply arm of the government. Arranging all the components in a hierarchy provides an overall view of the complex relationships and helps the decision maker to assess whether the elements in each level are of the same magnitude so that they can be compared accurately (Saaty 1990).

\section{Step two: Priority setting of the criteria by pairwise comparison (weighting)}

Rating the relative priority of the criteria is done by assigning a relative weight between one and nine to a criterion using Saaty's scale of relative importance. A value of nine is assigned to a particular criterion if its importance over the other is absolute while the other criterion gets the inverse (1/9). A value of one is assigned if the two elements being compared are equally important. The weightings were then normalized and averaged in order to obtain an average weight for each criterion. The criteria utilized for the assessment were quality, risk of contamination, sustainability, maintainability, energy requirement, greenhouse gas emission, technology requirement, seasonality, economy and public acceptance.

\section{Step three: pairwise comparison of options on each criterion (scoring)}

The six alternative water supply sources were compared with each other with respect to each criterion. Pairwise comparison can be a very cumbersome and confusing exercise when a large number of pairs is involved. The pairwise comparison was done by experts from University of Nigeria, Nsukka and Enugu State University of Science and Technology. For each criterion, the decision makers took time to compare two alternatives $A_{\mathrm{i}}$ and $A_{\mathrm{j}}$. After this, a pairwise comparison for the criterion was performed. Hence a total of 195 pairwise comparisons were performed by each expert. Since four experts were involved in the pairwise comparison, the arithmetic mean of the scores from the four decision makers was used to form the lower diagonal of the pairwise comparison 
matrix and the inverse of the values obtained was used to fill the corresponding elements of upper diagonal of matrix accordingly.

\section{Step four: Formulation of Pairwise Comparison Matrices}

For each criterion, an $n \times \mathrm{n}$ matrix was formed using the result of the pairwise comparison of alternatives. Where $n$ is the number of alternatives. A total of ten pairwise comparison matrices of alternatives and one criteria matrix were formed. The pairwise comparison matrix for steps 2 and 3 has a structure as shown below. Where, $a_{i j}=1 / a_{j i}$ if $m \neq n$; and $a_{i j}=1$ for $i=j$.

$A=\left(\begin{array}{ccccccc}1 & a_{12} & a_{13} & a_{14} & a_{15} & \ldots & a_{1 n} \\ a_{21} & 1 & a_{23} & a_{24} & a_{25} & \ldots & a_{2 n} \\ a_{31} & a_{32} & 1 & a_{34} & a_{35} & \ldots & a_{3 n} \\ \cdot & \cdot & . & . & \cdot & \ldots & . \\ \cdot & \cdot & . & . & . & \ldots & . \\ \cdot & \cdot & \cdot & . & . & \ldots & . \\ a_{m 1} & a_{m 2} & a_{m 3} & a_{m 4} & a_{m 5} & \ldots & 1\end{array}\right)$

\section{Step five: reduction of matrices}

The principal Eigen vectors of the pairwise comparison matrices of alternatives with respect to the criteria were obtained. This gives the weights of the different alternatives with respect to each criterion. In the same vein, the principal Eigen vectors of the normalized criteria matrix gave the relative weights of the criteria $\left(W_{j}\right) . W_{j}$ in each case refers to the weights of the alternatives with respect to the criterion. It has been shown that a good approximation of the principal Eigen vector can be obtained by obtaining the geometric mean of elements in each row to obtain a column matrix. Afterwards, each element in the column matrix is divided by the sum of the elements in the column.

\section{Step six: formulation of global matrix}

From the results gotten, a global matrix was formed using the normalized principal Eigen vectors of the alternatives with respect to each criterion for each column and the weights of the different criteria above each column. This was used to obtain the final rankings of the alternatives. From the global matrix, the final ranking was obtained as follows:

$\sum_{j=1}^{n} B_{i j} W_{j}$

$\mathrm{B}_{1,1}$ to $\mathrm{B}_{6,10}$ are the Eigen vectors corresponding to the weight of the alternatives with respect to each criterion. $W_{1}$ to $W_{10}$ are the Eigen vectors corresponding to the weights of the criteria.

\section{TOPSIS application}

After obtaining the global matrix which forms the terminal step for the AHP method, the criteria were grouped according to cost attributes denoted by $\mathbf{J}^{\prime}$. The cost attributes in this research include greenhouse gas emission, technology requirements, energy requirements, risk of contamination and seasonality while benefit attributes denoted by $\mathbf{J}$ include quality, public acceptance, economy, maintainability and sustainability (Table 2). The global matrix was normalized as follows:

$$
R=\left(r_{i j}\right)_{m \times n}, \text { where } r_{i j}=B_{i j} /\left(\sum B_{i j}^{2}\right)^{1 / 2} \text { for } i=1, \ldots, m ;
$$

$j=1, \ldots, n$. A weighted normalized matrix was constructed to give $v_{i j}=W_{j} r_{i j} . \mathrm{W}_{j}$ corresponds to the weight of the criteria and $r_{i j}$ corresponds to each element in the normalized matrix. The positive ideal $\left(A^{\prime}\right)$ and negative ideal $\left(A^{*}\right)$ solutions, respectively, are given by

$$
\begin{aligned}
A^{\prime} & =\left\{v_{1}^{\prime}, \ldots, v_{n}^{\prime}\right\}, \text { where } v_{j}^{\prime} \\
& =\left\{\min \left(v_{i j}\right) \text { if } j \in J ; \max \left(v_{i j}\right) \text { if } j \in J^{\prime}\right\}
\end{aligned}
$$

$$
\begin{aligned}
A^{*} & =\left\{v_{1}{ }^{*}, \ldots, v_{n}{ }^{*}\right\}, \text { where } v_{j}{ }^{*} \\
& =\left\{\max \left(v_{i j}\right) \text { if } j \in J ; \min \left(v_{i j}\right) \text { if } j \in J^{\prime}\right\}
\end{aligned}
$$

The above expressions imply that, for a cost criterion, the positive ideal solution is the water source with minimum value of $v_{i j}$; while for a benefit criterion, it is the source with maximum value. The reverse is the case for the negative ideal solution.

The separation measure from the positive ideal solution is given by

$S_{i}^{*}=\left[\sum\left(v_{j}^{*}-v_{i j}\right)^{2}\right]^{1 / 2}$,

where $v_{j}^{*}$ is the ideal solution of the alternatives with respect to criterion $\mathrm{j}$ and $v_{i j}$ is the weighted normalized vector corresponding to the alternatives with respect to criterion $\mathrm{j}$. The separation from the negative ideal alternative is

Table 2 Cost and benefit criteria

\begin{tabular}{ll}
\hline $\mathbf{J}$ (cost attributes) & $\mathbf{J}^{\prime}$ (benefit attributes) \\
\hline Risk of contamination & Economy \\
Seasonality & Quality \\
Technology requirement & Sustainability \\
Energy requirement & Maintainability \\
Greenhouse gas emission & Public acceptance \\
\hline
\end{tabular}


$S_{i}^{\prime}=\left[\sum\left(v_{j}^{\prime}-v_{i j}\right)^{2}\right]^{1 / 2}$

$v_{j}^{\prime}$ is the negative ideal solution of the alternatives with respect to criterion. Proximity to the ideal solution $\mathrm{Ci}^{*}$ was calculated as follows:

$\mathrm{Ci}^{*}=S_{i}^{\prime} /\left(S_{i}^{*}+S_{i}^{\prime}\right), 0<\mathrm{Ci}^{*}<1$,

where $S_{\mathrm{i}}^{*}$ is the separation from the ideal solution of alternative $i$ and $S_{\mathrm{i}}{ }^{\prime}$ is the separation from the negative ideal solution of alternative $i$. The option with $\mathrm{Ci}^{*}$ closest to 1 is the best option. The positive and negative ideal solutions have been highlighted in Tables 3 and 4 .

\section{Check for consistency}

In order to ensure the validity of results obtained, the pairwise comparison matrices were checked for consistency. Consistency check is a way of ensuring that experts' judgements were logical and not random. Random judgement can generate misleading results. Consistency in judgement is assessed using the consistency ratio (CR). If the CR is much in excess of 0.1 the judgments are unreliable and the exercise is valueless or must be repeated. The ratio of the consistency index (CI) to the random consistency index (RI) gives the consistency ratio. RI depends on the size of the matrix and was obtained from Saaty's table whereas CI is given by $\frac{\lambda_{\max }-n}{n-1}$, where $\lambda_{\max }$ is the average value of the principal Eigen vectors of the final matrix. The consistency ratios obtained for seasonality, maintainability, greenhouse gas emission, public acceptance and the criteria matrices fell within the acceptable range while those obtained for economy, sustainability, quality, risk of contamination, technology requirement and energy requirement fell outside the acceptable range. In order to improve the consistency of the matrices, the method proposed by Zeshui (2004) was adopted.

The algorithm for improving the consistency is as follows: For any $\mathrm{n} x \mathrm{n}$ judgement matrix $A=\left(\mathrm{a}_{\mathrm{ij}}\right)$, the approximation method is given by the following procedures:

Step 1: $\quad$ Let $A^{(0)}=\left(a_{\mathrm{ij}}^{(0)}\right)=\left(a_{\mathrm{ij}}\right)$, C.R.* ${ }^{*}=0.10$ and $k=0$.

Step 2: Calculate the maximum Eigen value $\lambda_{\max }\left(A^{(\mathrm{k})}\right)$ of $A^{(\mathrm{k})}$ and the normalized principal right eigenvector $\left(w_{1}^{(\mathrm{k})}, w_{2}^{(\mathrm{k})}, \ldots, w_{n}^{(\mathrm{k})}\right)^{\mathrm{T}}$.

Step 3: Calculate the consistency index C.I. ${ }^{(\mathrm{k})}=($ $\left.\lambda_{\max }\left(A^{(\mathrm{k})}\right)-n\right) \div(n-1)$ and the consistency ratio C.R. ${ }^{(\mathrm{k})}=$ C.I. ${ }^{(\mathrm{k})} \div$ R.I.

Step 4: If C.R. ${ }^{(k)}<$ C.R. ${ }^{*}$, then go to Step 7; otherwise, continue to the next step.

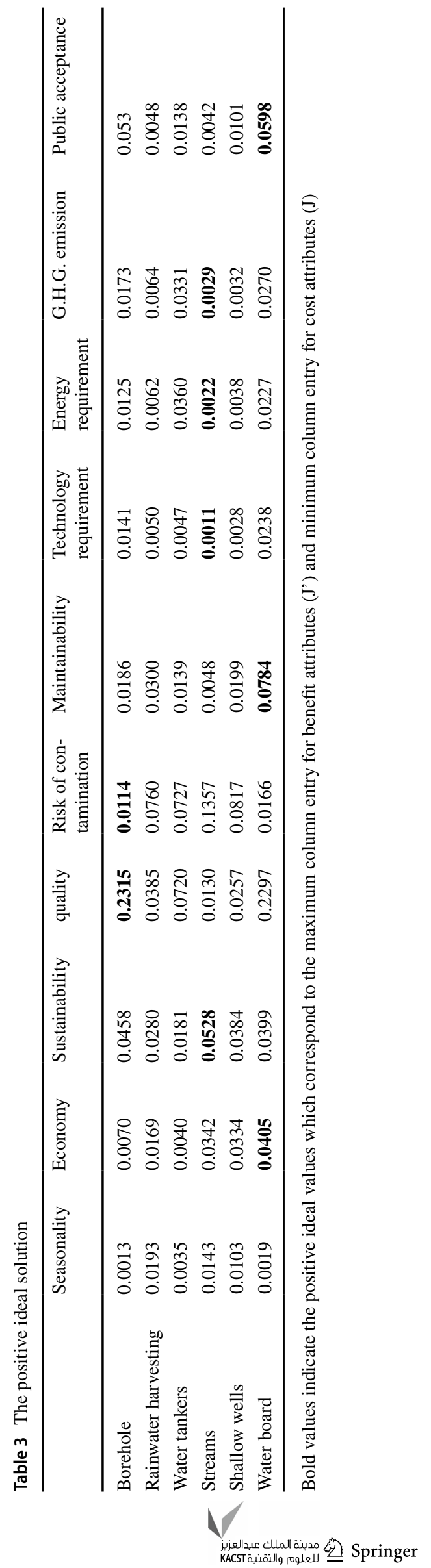




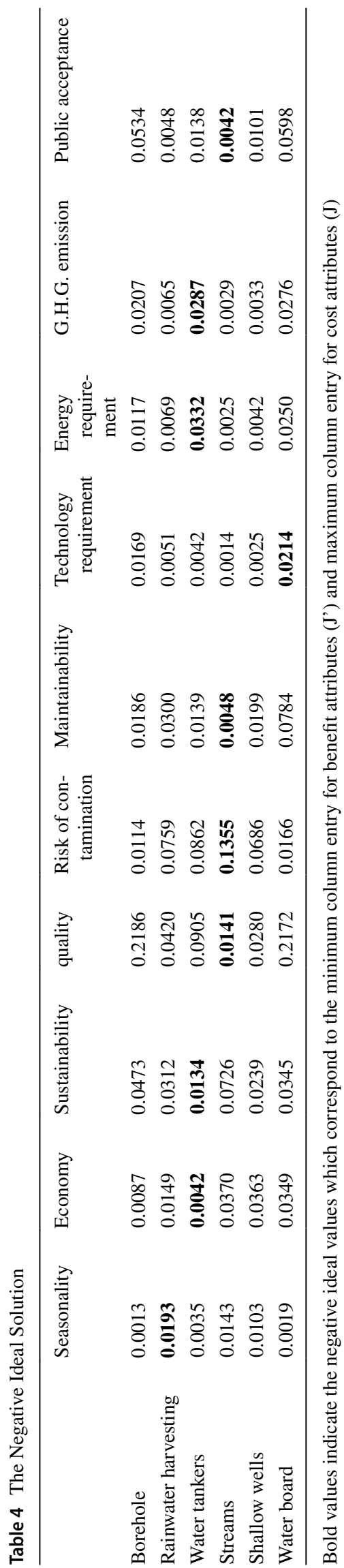

Step 5: Determine the element $\varepsilon_{r s}$ such that

$$
\begin{gathered}
\varepsilon_{r s}=\max _{i, j}\left\{a_{i j}^{(k)}\left(\frac{w_{j}^{(k)}}{w_{i}^{(k)}}\right\}_{0}\right. \\
\text { Let } A^{(\mathrm{k}+1)}=\left(a_{\mathrm{ij}}^{(\mathrm{k}+1)}\right) \text { where } a_{\mathrm{ij}}^{(\mathrm{k}+1)} \text { is calculated from } \\
a_{i, j}^{(k+1)}= \begin{cases}\lambda a_{r s}^{(k)}+(1-\lambda)\left(w_{r}^{(k)} / w_{s}^{(k)}\right) & (i, j)=(r, s) \\
\frac{1}{\lambda a_{r s}^{(k)}+(1-\lambda)\left(\frac{w_{r}^{(K)}}{w_{s}^{(k)}}\right)} & (i, j)=(s, r) \\
a_{i, j} & (i, j) \neq(r, s),(s, r)\end{cases}
\end{gathered}
$$

Step 6: Let $k=\mathrm{k}+1$, and return to Step two.

Step 7: Output $k, A^{(\mathrm{k})}, \lambda_{\max }\left(A^{(\mathrm{k})}\right)$; C.R. ${ }^{(\mathrm{k})}$ and $w^{(\mathrm{k})}$, then $A^{(\mathrm{k})}$ is the modified judgement matrix and $\mathrm{w}^{(\mathrm{k})}$ is the priority vector.

Step 8: End. $k$ represents the $k$ times of iteration, and $\lambda \in(0,1)$.

The value of $\lambda$ used is 0.1 and the number of iterations done before getting the new consistencies is shown in Table 5.

\section{Modification of TOPSIS method}

A careful examination of the separation from the positive ideal and negative ideal solution shows that the distance between the two ideal solutions varies for each alternative. It is believed that the separation between the negative ideal and positive ideal solutions should be equal for all alternatives so as to provide equal basis for obtaining the proximity to the ideal solution. Hence, in order to address this problem, the separation from the positive and negative ideal solutions was normalized as follows:

$S_{i}^{* *}=\frac{\operatorname{Max}\left(S_{i}^{*}+S_{i}^{\prime}\right)-\left(S_{i}^{*}+S_{i}^{\prime}\right)}{2}+S_{i}^{*}$

$S_{i}^{\prime \prime}=\frac{\operatorname{Max}\left(S_{i}^{*}+S_{i}^{\prime}\right)-\left(S_{i}^{*}+S_{i}^{\prime}\right)}{2}+S_{i}^{\prime}$

$S_{\mathrm{i}}^{*}$ and $S_{\mathrm{i}}{ }^{\prime}$ are separations from the positive ideal solution and positive ideal solution, respectively, as originally obtained by the TOPSIS method. $S_{\mathrm{i}}^{* *}$ and $S_{\mathrm{i}}{ }^{\prime \prime}$ are the normalized separations from the positive ideal solution and positive ideal solution, respectively. This is equivalent to moving the location of the negative ideal solution to the left and the positive ideal solution to the right by equal distances. This operation makes the locations of the ideal solutions to coincide with those of the alternative with the longest separation between ideal solutions, i.e. $\operatorname{Max}\left(S_{\mathrm{i}}^{*}+S_{\mathrm{i}}{ }^{\prime}\right)$. Hence the proximity to the ideal solution was then recomputed as follows:

$C_{i}^{*}=S_{i}^{\prime \prime} /\left(S_{i}^{* *}+S_{i}^{\prime \prime}\right), 0<\mathrm{Ci}^{*}<1$ 
Table 5 Original and improved consistency ratios

\begin{tabular}{lllll}
\hline Pairwise comparison matrix & Original CR & Remark & Number of iterations & $\begin{array}{l}\text { New CR } \\
(\lambda=0.1)\end{array}$ \\
\hline Criteria matrix & 0.099 & Satisfactory & - & - \\
Economy & 0.270 & Not satisfactory & 4 & 0.063 \\
Energy requirement & 0.157 & Not satisfactory & 2 & 0.046 \\
Greenhouse gas emission & 0.102 & Satisfactory & - & - \\
Maintainability & 0.107 & Satisfactory & - & - \\
Public acceptance & 0.075 & Satisfactory & - & - \\
Quality & 0.131 & Not satisfactory 2 & 0.067 \\
Risk of contamination & 0.111 & Not satisfactory & 1 & 0.057 \\
Seasonality & 0.084 & Satisfactory & - & - \\
Sustainability & 0.660 & Not satisfactory & 8 & 0.045 \\
Technology requirement & 0.182 & Not satisfactory & 5 & 0.076 \\
\hline
\end{tabular}

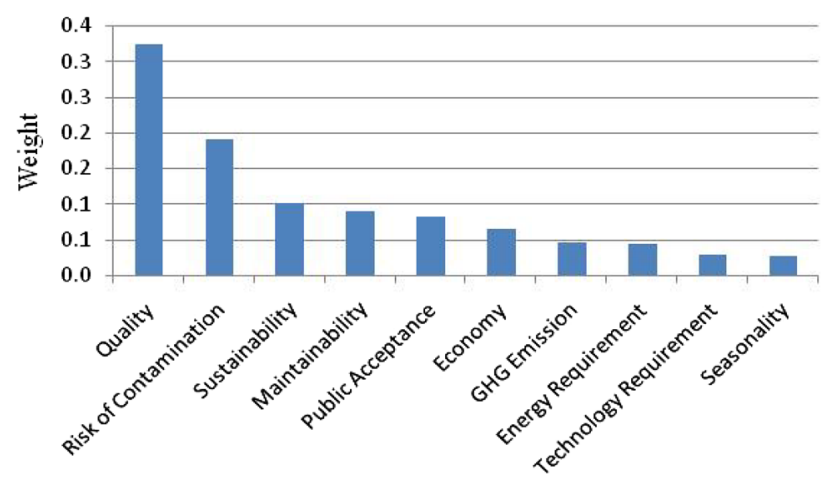

Criteria

Fig. 1 Weights of criteria obtained from pairwise comparison

\section{Results}

The most important criteria which were found to affect the ranking of water sources for domestic water supply are quality, risk of contamination, sustainability, maintainability and public acceptance (see Fig. 1). Figure 1 was plotted with criteria weights obtained in step two as outlined in the methodology. These five criteria accounted for roughly $79 \%$ of the ranking while the other five criteria: economy, GHG emission, energy requirement, technology requirement and seasonality, accounted for the remaining $21 \%$. Quality alone weighed 0.33 which amounts to $33 \%$ while risk of contamination weighed 0.19 which amounts to $19 \%$.

The rankings obtained by AHP and TOPSIS methods are shown in Tables 6 and 7. The two methods applied (AHP and TOPSIS) yielded slightly different results. While AHP ranked the water sources in order of preference as follows: borehole $>$ water board $>$ water tankers $>$ streams $>$ rainwater harvesting $>$ shallow wells;
TOPSIS ranked them as follows: water board $>$ borehole $>$ water tankers $>$ rainwater harvesting $>$ shallow well $>$ streams. Borehole was ranked the best supply source by the AHP method with a rank of $31.8 \%$, followed by water board with $27.2 \%$, water tankers with $15 \%$ and the least desirable supply source being shallow wells with $10.4 \%$. However, according to the TOPSIS method, the supply source closest to the ideal solution is the water board with a score of 0.87 , followed by borehole at 0.79 , water tankers at 0.31 and the source farthest from the ideal solution is streams with 0.21 as the score.

\section{Discussion}

\section{Effect of criteria on water source selection}

Figure 1 showed that quality criteria (water quality and risk of contamination) weighed heavily on the ranks obtained using the two methods. This is reasonable because water for consumption and other domestic uses should be of high quality and pose no health risks. Consumption of unwholesome water has been implicated in several outbreaks of water born diseases. Quality and risk of contamination are somewhat similar in the same way sustainability and maintainability are similar, hence the closeness in rank. However, quality deals with the insitu characteristics of the water at source while risk of contamination deals more with the possibility of contamination in the course of abstraction and conveyance. Besides, the quality of water from any source will also affect other criteria such as economy, energy requirement, technology requirement, public acceptance and GHG emission. Water of high quality will require minimal treatment thereby minimizing cost. During water treatment, energy is required for aeration, pumping, mechanical mixing, heat supply, etc. Hence the higher the quality of water, the lower the required energy input per cubic meter of water. This goes

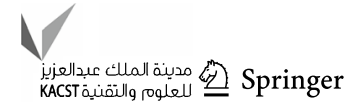




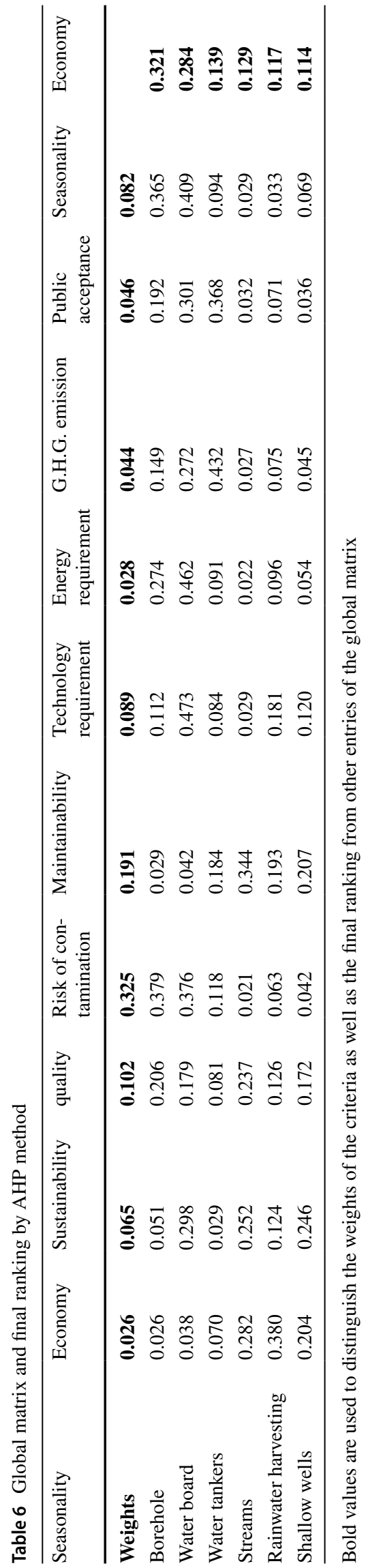

Table 7 Global matrix and final ranking by TOPSIS method

\begin{tabular}{lc}
\hline Water source & Rank \\
\hline Water board & 0.865 \\
Borehole & 0.778 \\
Water tankers & 0.313 \\
Rainwater harvesting & 0.280 \\
Shallow wells & 0.271 \\
Streams & 0.209 \\
\hline
\end{tabular}

a long way to explain why quality accounts for one-third of the entire criteria weight while the other nine criteria account for two-thirds. Seasonality and technology requirements weighed the least among the criteria, 2.65 and $2.82 \%$, respectively. This implies that taking the criteria separately without associating them to any particular water source, seasonality and technology requirement are the least important of all the criteria considered. If this study was conducted several decades ago, seasonality would probably top the criteria list because the primary water sources (rainwater and streams) are highly sensitive to seasonal water variations. However, since most urban dwellers depend on boreholes, water vending and government owned water boards which respond only marginally to seasonal water variations, the effect of seasonality has been downplayed. Besides, the effect of seasonality as a water supply criterion is likely to be more pronounced in arid and semi arid regions with scanty and short period of annual rainfall. Table 8 shows how certain criteria affect the selected water sources as elicited from the literature. It should be noted that the effects as perceived by the authors are strongly dependent on the geographical location of study.

\section{Ranking of water sources by AHP and TOPSIS}

The results obtained clearly and naturally grouped the water sources into two. Water board and borehole belong to the higher hierarchy with TOPSIS ranking greater than 0.7 while water tanker, rainwater harvesting, shallow well and streams belong to the lower echelon with TOPSIS ranking less than 0.35 . None of the sources fall within the intermediate class. The only problem with borehole as a domestic water supply source in developing countries is the initial capital cost required for its construction which is beyond the reach of many. However, some house owners now provide boreholes for their tenants and the cost is built into the rent which the tenants can conveniently pay. Over the years there has been a sharp and steady decline of the percentage of urban population connected to public water mains in Nigeria. This is partly because of population explosion which has overstretched public water facilities and also because of corruption, poor maintenance culture, vandalization, lack of commitment on part of the water board staff and 
Table 8 Effect of criteria on selection of water supply sources

\begin{tabular}{|c|c|c|c|c|c|c|c|}
\hline \multirow[t]{2}{*}{ Criteria } & \multicolumn{6}{|c|}{ Water source } & \multirow[t]{2}{*}{ References } \\
\hline & Borehole & Rainwater harvesting & Water tankers & Water board & Shallow wells & Streams & \\
\hline Seasonality & Low & Extreme & Low & Moderate & Very high & Extreme & $\begin{array}{l}\text { Akpan (2005); Ola- } \\
\text { juyigbe, Rotowa and } \\
\text { Adewumi (2012) }\end{array}$ \\
\hline Economy & Very high & Moderate & Low & Extreme & High & Very high & $\begin{array}{l}\text { Whittington, Lauria and } \\
\text { Mu (1991) }\end{array}$ \\
\hline Sustainability & High & Very high & Low & Very high & Moderate & Low & $\begin{array}{l}\text { Waite (2010); Alley, } \\
\text { Reilly, and Franke } \\
\text { (1999). }\end{array}$ \\
\hline Quality & Very high & Moderate & Moderate & Extreme & Moderate & Low & $\begin{array}{l}\text { Olajuyigbe et al. (2012); } \\
\text { Sridhar, Coker, and } \\
\text { Adegbuyi (2001) }\end{array}$ \\
\hline Risk of contamination & Low & Moderate & High & Low risk & High & Very high & $\begin{array}{l}\text { State Government of } \\
\text { Victoria }(2015)\end{array}$ \\
\hline Maintainability & Moderate & High & Very high & Extreme & High & High & $\begin{array}{l}\text { Brikké and Bredero } \\
\text { (2003) }\end{array}$ \\
\hline Technology requirement & High & Moderate & Low & Very high & Low & Low & $\begin{array}{l}\text { Brikké and Bredero } \\
\text { (2003) }\end{array}$ \\
\hline Energy Requirement & Low & Very high & High & High & Low & Low & $\begin{array}{l}\text { Reffold, Leighton, } \\
\text { Choudhury, and } \\
\text { Rayner (2008); } \\
\text { Retamal, Glassmire, } \\
\text { Abeysuriya, Turner } \\
\text { and White (2009) }\end{array}$ \\
\hline $\begin{array}{l}\text { Green house gas emis- } \\
\text { sion }\end{array}$ & Moderate & Very high & High & High & Low & Low & $\begin{array}{l}\text { Reffold et al. (2008); } \\
\text { Way, Martinson, Hes- } \\
\text { lop and Cooke (2010) }\end{array}$ \\
\hline Public acceptance & Very high & Low & Moderate & Extreme & Low & Low & Olajuyigbe et al. (2012) \\
\hline
\end{tabular}

total neglect. Hence, though water board ranked very high alongside borehole, a greater percentage of the population is not connected and hence cannot directly get water from the water board. For several decades, water tankers have gradually but steadily formed the hub of domestic water supply in most Nigerian cities, and even rural areas, because of the failure of water boards to meet water demand. A recent survey by the researchers in southeastern Nigeria revealed that more than $40 \%$ of residents depend on water tankers for domestic water supply. Olajiyugbe et al. (2012) found that $90.6 \%$ of households surveyed in Festac Town, Lagos, depends on vended water for domestic supply. Water tankers are preferred to the other sources of water such as rainwater, streams and shallow wells because of their perceived superior quality. Though some of these tankers obtain their water from reliable sources (borehole and water board), the risk of contamination during conveyance and discharge is very high. Olajuyigbe et al. (2012) opined that this overdependence on water tankers is because it is cheaper than water supplied by government-owned water board. However, this is not entirely true because most water boards in the country do not use meters for measuring water supplied to homes resulting in gross underpayment for water consumed. A family of six in Enugu will require 9000 litres of water per month (assuming a basic water need of $50 \mathrm{~L}$ per capita per day). If this family gets water from tankers they would spend about N11363 (\$50), but if they get water from the water board they would pay just about N2000 (\$8.70). It is, therefore, obvious that massive reliance on water tankers and other forms of water vending is neither as result of lower cost or more convenience but because of lack of access to water from public mains. The result of our study suggests that water supplied by tankers is not much better than rainwater, streams and shallow wells, except perhaps in terms of quality. This implies that the overdependence on water tankers is both unjustifiable and unsustainable. Whittington, Lauria and Mu (1991) observed that, on annual basis, households in Onitsha, Nigeria pay water vendors over twice the amount required to operate and maintain a piped distribution system. In some cases, the source of water supplied by tankers cannot be guaranteed especially during periods of peak demand or scarcity.

Going by the results of this research, those who are not connected to the water board and borehole can achieve sustainable water supply by a combination of the different sources. Where possible, borehole and water board can be 
used as sources of potable water supply, while other sources such as stream, rainwater and shallow well can be harnessed for other purposes not requiring high quality water. The assessment of rainwater in this study by experts was based on current practices of rainwater harvesting which are predominantly traditional. This is probably why rainwater was ranked very low. However, rainwater can be a valuable resource and can be quite safe to drink when harvested and stored in a properly installed and maintained water catchment system (Olaoye and Olaniyan 2012). The increase in cost of installing collection, filtration and storage units will be more than compensated for by improved quality, reduced risk of contamination, reduced sensitivity to seasonality, increased sustainability as well as increased public acceptance. The cost of installing rainwater harvesting facility is far less than the cost of borehole construction and so is the energy requirement as well as greenhouse gas emission. Otti (2011) observed that the cost of a complete rainwater harvesting system is about half the cost for sinking a borehole for the same yield.

\section{Effect of consistency adjustment on ranks}

After adjusting the pairwise comparison matrices for consistency, ranking was repeated using the AHP and TOPSIS. The global matrix was formulated and the ranks of the water sources were obtained as earlier discussed. Since the criteria matrix was originally consistent, the criteria weights were not affected. Improvement in consistencies of the pairwise comparison matrices did not affect the order of ranking obtained by AHP but there was a slight change in the TOPSIS result. For TOPSIS, shallow well displaced rainwater harvesting downward. Besides, minor variations were observed in the values of the ranks for all water sources for both AHP and TOPSIS. It was observed that some ranks decreased while some other increased. Stream was the most affected for TOPSIS with $15.32 \%$ increase in rank while water tanker was the most affected for AHP with the rank increasing by $9.1 \%$. The least affected for AHP was water board with the rank decreasing by $1.34 \%$; while the least affected for TOPSIS was borehole with a decrease of $1.42 \%$ in rank. Obviously, these changes are insignificant given that there was no rank reversal except for shallow well and rainwater harvesting which exchanged position in the TOPSIS method. This goes to prove that the pairwise comparisons were objectively executed and therefore reliable. The beauty of the TOPSIS method is its ability to show at a glance, from the table of ideal positive and negative solutions, which criteria have the most and least effect, respectively, on the alternatives. It can also be seen that improving the consistency of the matrices did not result in any drastic changes in the order of the alternatives in both methods though the values of all the ranks were altered. The little discrepancies in the results obtained by the two approaches should not be a problem in the decision making process as Multi-Criteria Decision Making only serves as a reliable aid in making decisions and so the decision making is solely left to the principal decision maker based on the results gotten from the MCDM.

\section{Effect of modification of TOPSIS method on ranks}

The effect of normalizing the separations from the negative ideal and positive ideal solutions can be visualized by plotting them on the Cartesian plane as depicted in Fig. 2. As can be clearly seen, whereas the plot for the original values yield a scatter plot which can roughly be described by a power law, the plots of the normalized separations yield a perfectly straight line. The effect of normalizing the separation from the ideal solution resulted in a minor adjustment of ranks with rainwater slightly overtaking well water (Table 9). It appears reasonable that rainwater should be higher in rank than shallow well because small scale rainwater harvesting can be done at no cost and rainwater also ranked higher than well water in quality. The major setback of rainwater is that it is extremely sensitive to seasonality which does not affect well water as much. However, this drawback can be overcome by the installation of storage tanks which can hold water throughout the dry season. This practice is now being adopted by property owners. Another effect of normalizing the separation from the ideal solutions is that alternatives with original ranks greater than 0.5 were slightly reduced while those with ranks less than 0.5 were slightly increases. A similar trend was also observed with the consistency adjustment done in the previous section (see Table 9)

A pictorial depiction of the TOPSIS result has been presented in Fig. 3. Another advantage of the TOPSIS method over the AHP method is that it not only rank alternatives relative to one another, but also demonstrates how close the alternatives are to the ideal situation. Figure 3 suggests that water board and borehole are the closest to the ideal domestic water supply situation while water tanker, rainwater harvesting, shallow well and streams are far removed for ideality and are, therefore, not sustainable as currently practiced. The reason stream is the farthest from the ideal solution is because many streams in urban areas have been converted to refuse and sewage dumps thereby rendering them unusable. This is in addition to the unregulated discharge of untreated industrial effluents which hardly gives room for self-purification, thus keeping the streams in a perpetually polluted state. Shallow wells also suffer similar fate (but to a lesser degree) because of the intrusion of agricultural and industrial runoff. The results, therefore, suggest that none of the water supply sources is exactly ideal. However, the ones with most proximity to the ideal solution (borehole and water board) can be 
a

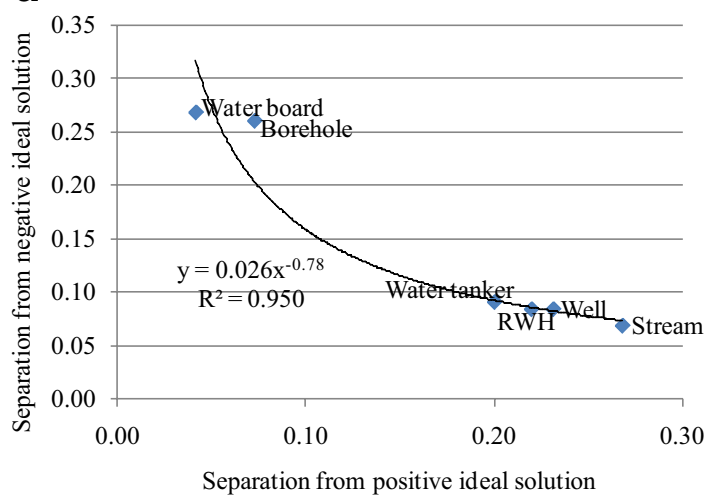

C

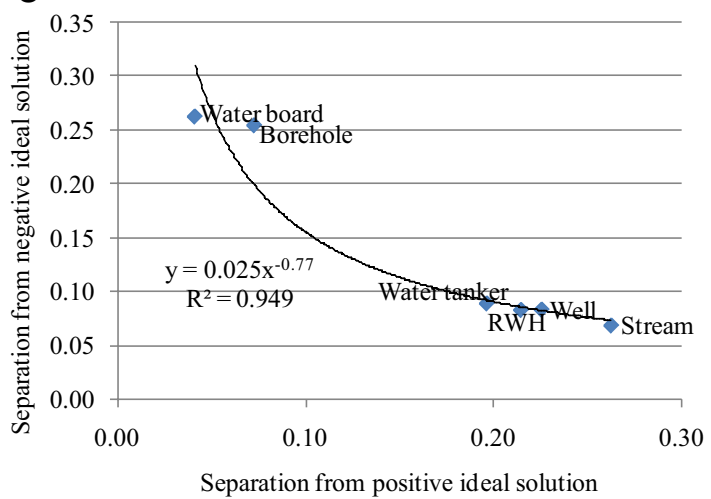

b

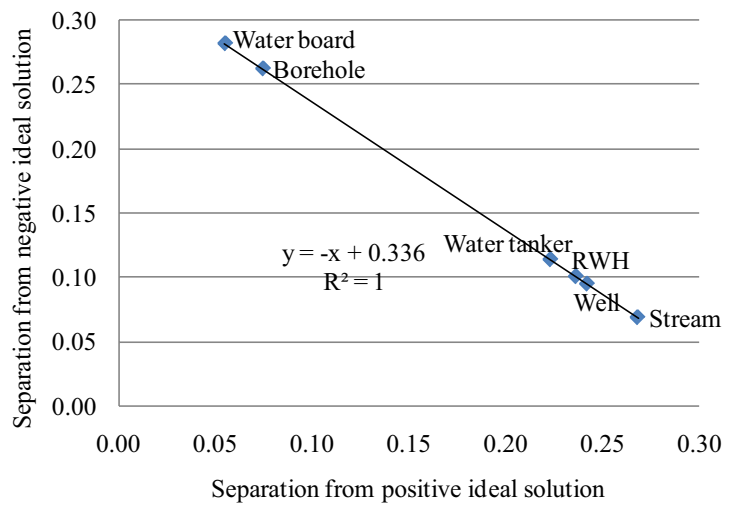

d

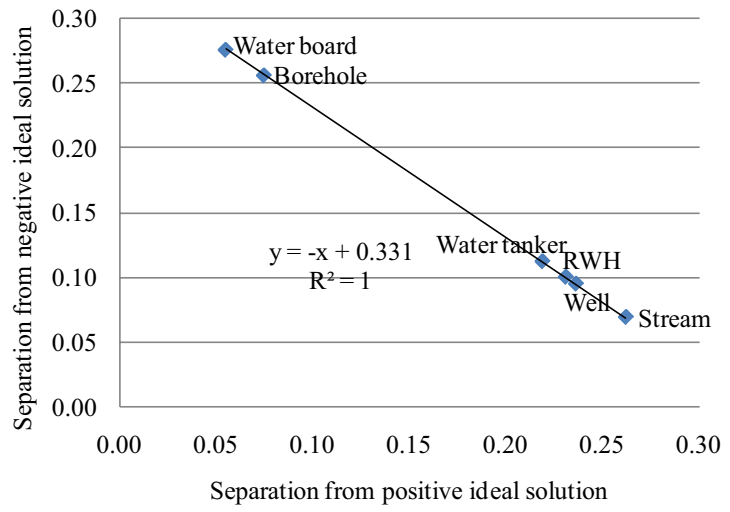

Fig. 2 Plots of separation from ideal solutions for a TOPSIS before consistency amendment $\mathbf{b}$ TOPSIS after consistency amendment $\mathbf{c}$ Modified TOPSIS before consistency amendment $\mathbf{d}$ Modified TOPSIS after consistency amendment

Table 9 Summary of ranking by TOPSIS

\begin{tabular}{|c|c|c|c|c|c|c|c|}
\hline \multicolumn{4}{|c|}{ Before consistency adjustment } & \multicolumn{4}{|c|}{ After consistency adjustment } \\
\hline \multicolumn{2}{|l|}{ TOPSIS } & \multicolumn{2}{|c|}{ Modified TOPSIS } & \multicolumn{2}{|l|}{ TOPSIS } & \multicolumn{2}{|c|}{ Modified TOPSIS } \\
\hline Water board & 0.865 & Water board & 0.834 & Water board & 0.824 & Water board & 0.798 \\
\hline Borehole & 0.778 & Borehole & 0.774 & Borehole & 0.767 & Borehole & 0.756 \\
\hline Water tankers & 0.313 & Water tankers & 0.339 & Water tankers & 0.338 & Water tankers & 0.365 \\
\hline RWH & 0.280 & RWH & 0.303 & RWH & 0.290 & RWH & 0.315 \\
\hline Shallow wells & 0.271 & Shallow wells & 0.287 & Shallow wells & 0.284 & Shallow wells & 0.308 \\
\hline Streams & 0.209 & Streams & 0.209 & Streams & 0.24 & Streams & 0.241 \\
\hline
\end{tabular}

used as potable water sources while the others can be relied upon for non-potable purposes.

\section{Conclusion}

The results of the AHP and TOPSIS methods gave similar but non-identical results. While AHP ranked borehole as the best followed by water board, TOPSIS ranked water board as the best followed by borehole. However, in both cases, the difference in rank between the two was not pronounced
(11.43\% for AHP and $10.04 \%$ for TOPSIS). Consistency amendment did not alter the general order of the results either; although the values of ranks were slightly altered. Water board and borehole were far ahead of the other sources in rank. Quality and risk of contamination were rated as the most important criteria and outweighed the other eight criteria put together. This paper shows that water quality has an overriding influence on the selection of domestic water sources in developing countries. Though borehole and water board are usually of better quality than other sources, they are usually beyond the reach of the average citizen. Hence, 

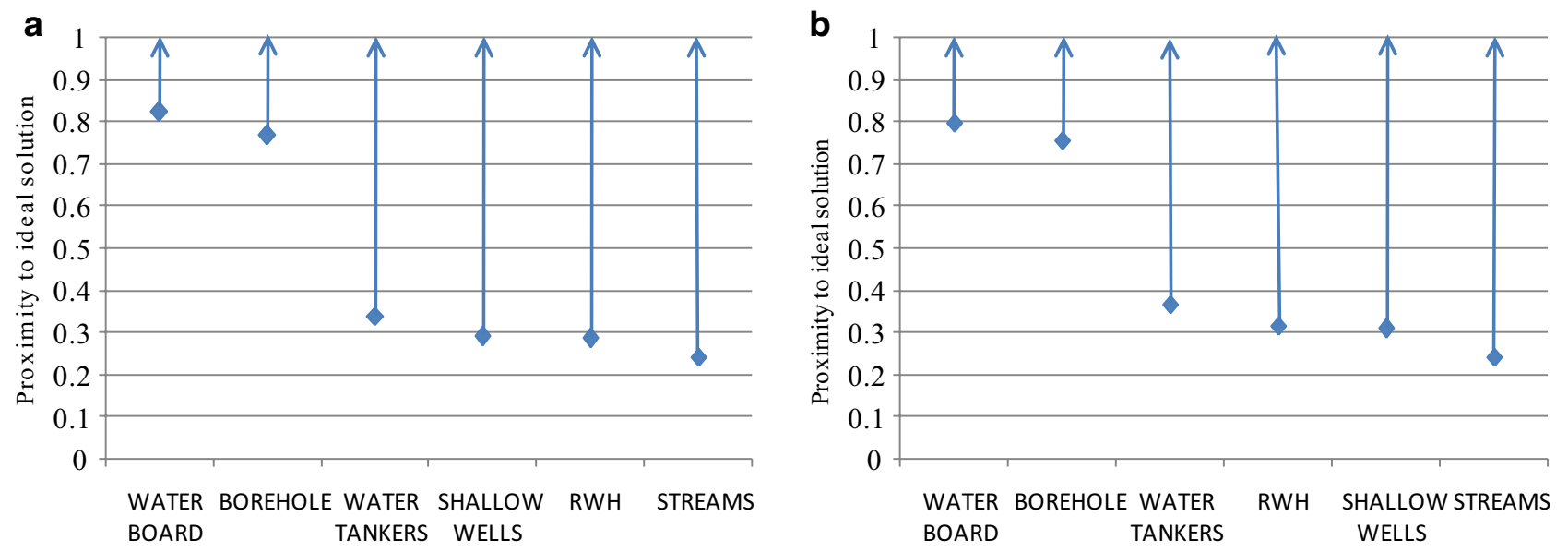

Fig. 3 Ranking (plots of proximity to the ideal solution) for a TOPSIS and $\mathbf{b}$ modified TOPSIS, after consistency amendment

given the current situation of water supply, the best approach for domestic water supply is a combination of two or more sources. Where tenable, borehole and water board should be used as sources of potable water while other sources should be used for other non-potable purposes. There is need to mention that the results obtained from this study are not rigid but would vary if the study was conducted in another location with different hydrological and socio-economic conditions.

Open Access This article is distributed under the terms of the Creative Commons Attribution 4.0 International License (http://creativecomm ons.org/licenses/by/4.0/), which permits unrestricted use, distribution, and reproduction in any medium, provided you give appropriate credit to the original author(s) and the source, provide a link to the Creative Commons license, and indicate if changes were made.

\section{References}

Adeoye PA, Adeolu AR, Ibrahim HM (2013) Appraisal of rural water supply: case study of Kwara State, North Central Nigeria. Int J Basic Appl Sci 1(4):816-826

Akpan AJ (2005) The role of water vendors in the Apapa/Iganmu, Alimosho, Shomolu, Ajeromi and Ifelodun Areas of Lagos. SLGP Consultants' Report Number 812

Alley WM, Reilly TE, Franke O (1999) Sustainability of Groundwater Resources, US Geological Survey Circular 1186

Al-Zubi Y, Shatanawi M, Al-Jayoussi O, Al-Kharabsheh A (2002) Application of decision support systems for sustainable management of water resources in the Azraq basin-Jordan. Water Int 27(4):532-541

Awadallah AG, Awadallah NA (2014) An integrated water resources and economic approach for optimizing water allocation policies. J Water Res Protect 6:1444-1456

Brikké F, Bredero M (2003) Linking technology choice with operation and maintenance in the context of community water supply and sanitation A reference document for planners and project staff. World Health Organization, Geneva, pp 1-136
Carter RC, Tyrrel SF, Howsam P (1999) Impact and sustainability of community water supply and sanitation programmes in developing countries. J Char Ins Water Environ Manag 13:292-296

El-Gafy IK, El-Ganzori AM, Mohamed AI (2013) Decision support system to maximize economic value of irrigation water at the Egyptian governorates meanwhile reducing the national food gap. Water Science 27(54):1-18

El-Zayat A (2014) Nile basin water strategy. Int J Environ Water 3(5):198-206

Giupponi C, Sgobbi A (2013) Decision support systems for water resources management in developing countries: learning from experiences in Africa. Water 5:798-818

Jaber JO, Mohsen MS (2001) Evaluation of non-conventional water resources supply in Jordan. Desalination 136:83-92

John-Dewole OO (2012) Adverse effects of inadequate water supply on human health: a case study of Kajola Local Government in Oyo State, Nigeria. Greener J Med Sci 2(5):115-119

Lade O, Oloke D, Chinyio E, Fullen M (2012) Use of Multi-criteria Decision Analysis Methods for Water Supply Problems: a Framework for Improved Rainwater Harvesting. J Environ Sci Eng A 1:909-917

Lasage, R. (2007). A multi-criteria analysis of water management strategies in Kitui, Kenya. Institute For Environmental Studies, Report W-07/14

Mark M, Tafadwa T (2015) The Domestic Water Supply Puzzle in Zimbabwean Cities: challenges and Opportunities for Mtapa Residential Suburb, Gweru, Zimbabwe. International Journal of Humanities and Social Science 5(1):123-133

Miller KA, Belton V (2014) Water resources management and climate change adaptation: a holistic and multi-criteria perspective. Mitig Adapt Strat Glob Change 19(3):289-308

Musungu K, Motala S, Smit J (2012) Using multi-criteria evaluation and GIS for flood analysis in informal settlements of Cape Town: the case of Graveyard Pond. South African Journal of Geomatics 1(1):77-91

Mutikanga HE, Sharma SK, Vairavamoorthy K (2011) Multi-criteria decision analysis: a strategic planning tool for water loss management. Water Resour Manage 25(14):3947-3969

Okeola O, Sule BF (2012) Evaluation of management alternatives for urban water supply system using multicriteria decision analysis. J King Saud Univ 24(1):19-24

Olajuyigbe AE, Rotowa OO, Adewumi IJ (2012) Water vending in Nigeria. Medit J Soc Sci 3:229-238 
Olaoye RA, Olaniyan OS (2012) Quality of rainwater from different roof material. Int J Eng Technol 2(8):1413-1421

Othman F, Heydari M, Sadeghian MS, Rashidi M, Parsa MS (2014) The necessity of systematic and integrated approach in water resources problems and evaluation methods, a review. Adv Environ Biol 8(19):307-315

Otti V (2011) Economic advantage of rainwater harvesting over water borehole: a sustainable development at the Extension Site Federal Polytechnic, Oko. Int J Water Res Environ Eng 3(4):73-76

Pietersen K (2006) Multiple criteria decision analysis (MCDA): a tool to support sustainable management of groundwater resources in South Africa. Water SA 32(2):119-128

Prasad KC, Strzepek KM van Koppen B (2004). Addressing socioeconomic objectives through enhanced decision support systems for water resources management: Vision, gaps and challenges in South Africa. In Proceedings of International Conference on Politics and Information Systems, Technologies and Applications (PISTA), Orlando, Florida, USA, 21-25 July 2004, pp 182-187

Ramsar Convention Secretariat (2010), Water allocation and management: Guideline for the allocation and management of water for maintaining the ecological functions of wetlands. Ramsar Handbook for the Wise Use Wetlands $\left(4^{\text {th }} \mathrm{Ed}\right)$, Vol. 10, Ramsar Convention Secretariat, Gland, Switzerland

Reffold EW, Leighton F, Choudhury F, Rayner P (2008) Greenhouse gas emissions of water supply and demand management options. Environmental Agency, Bristol

Rematal M, Glassmire J, Abeysuriya K, Turner A, White S (2009) The Water- Energy Nexus: Investigation into the energy implications of household rainwater systems. University of Technology, Sydney, Institute for Sustainable Futures

Saaty TL (1990) How to make a decision: the analytic hierarchy process. Eur J Oper Res 48:9-26

Saaty T (2008) Decision making with the analytic hierarchy process. Int J Serv Sci 1(1):83-98

Sridhar, M. K., Coker, A. O., and Adegbuyi, S. A. (2001). Rainwater harvesting in Nigeia: Prospects and problems. In Proceedings of the $10^{\text {th }}$ International Rainwater Catchment Systems Conference, September 10-14, Mannheim, Germany, 122
State Government of Victoria (2015). Water-tanks, bores and dams, Better Health Channel, retrieved from m.betterhealth.vic.gov.au/ bhcv2/bhcarticles.nsf/mskpages/water_tanks_bores_dams?o pen

Tecle A, Duckstein L (1994) Concepts of multicriterion decision making. In: Bogardi JJ, Nachtnebel HP (eds) Multicriteria analysis in water resources management. UNESCO, Paris, pp 33-62

Teshome A, de Graaff J, Stroosnijder L (2014) Evaluation of soil and water conservation practices in the north-western Ethiopian highlands using multi-criteria analysis. Front Environ Sci 2:1-13

Tshikolomo KA, Nesamvuni AE, Stroebel A, Walker S (2012) Water supply and requirements of households in the Luvuvhu-Letaba water management area of South Africa. Int J Bus Soc Sci 3(3):37-49

Ukpong EC, Okon BB (2013) Comparative analysis of public and private borehole water supply sources in Uruan Local Government Area of Akwa Ibom State. Int J Appl Sci Technol 3(1):76-91

Velasquez M, Hester P (2013) An analysis of multi-criteria decision methods. Int J Oper Res 10(2):56-66

Waite M (2010) Sustainable water resources in the built environment. IWA Publishing, London, UK

Way CM, Martinson DB, Heslop SE, Cooke RS (2010) Rainwater harvesting: environmentally beneficial for the UK? Water SciTechnol 10(5):776-782

Whittington D, Lauria D, Mu X (1991) A study of water vending and willingness to pay for water in Onitsha, Nigeria. World Develop 19(2/3):179-198

Zeshui X (2004) A practical method for improving consistency of judgement matrix in the AHP, Nanjing, China. J Syst Sci Complexity 17(2):169-175

Publisher's Note Springer Nature remains neutral with regard to jurisdictional claims in published maps and institutional affiliations. 